Original Research Paper

\title{
Increasing Learning Frequency through Education Based Game
}

\author{
Dennise Adrianto, Violitta Yesmaya and Alvin Chandra \\ Department of Computer Science, School of Computer Science, Bina Nusantara University, Jakarta, Indonesia
}

Article history

Received: 27-11-2013

Revised: $10-04-2014$

Accepted: 30-04-2015

Corresponding Author:

Dennise Adrianto

Department of Computer

Science, School of Computer

Science, Bina Nusantara

University, Jakarta, Indonesia

Email: dadrianto@binus.edu

\begin{abstract}
In the era of globalization, the development of the gaming world is evident very quickly, evidenced by the launch of various types of games every year, even every month. Game development that grows rapidly makes the desire to incorporate educational elements into the game application. It is also supported by the development of game engine to facilitate game development. The purpose of this research is to build an education based game on PC platform using Unity3D Game Engine (the newest game engine) to increase the learning frequency. The result achieved in this result is the creation of an educational based game app as a medium of study by combining the concept of the game and learning in it. Conclusion obtained after doing this research is that education based game can be made to increase the learning frequency.
\end{abstract}

Keywords: Game, Education Based Game, Unity3D, Learning Frequency

\section{Introduction}

Information technology always grows rapidly every year and becoming individual needs. One of the information technologies that grow rapidly is computer. With the rapid development, we can gain some benefits like a learning method for children using a computer-based multimedia.

Multimedia is a combination of text, image, sound, animation and video that interact with each other and form a harmonious whole. One form of multimedia which can apply the teaching method is game (Vaughan, 2010).

In general, game is a problem solving activity to using an approach that wants the fun attitude. Game is also an alternative media that not only provide comfort and entertainment, but also can provide obstacles and challenges to solve a problem. Several types of games that developed today in Indonesia are role-playing games, education games, strategy games, action games and many more. One type of game development that quite large and popular is Role Playing Game (RPG).

RPG is a game that the player controls one or more characters, typically design by the player and guides them through a series of quests managed by the computer. Victory consists of completing these quests, character growth in power and abilities is a key feature of the genre (Adams, 2013).
According to the study conducted by Irianto (2009), learning to use multimedia in learning activities can be improve students understanding concept and to motivate the learning process, so that more students can concentrate and attention in follow the lesson, because the use of the interesting media.

From all that has been described above, the authors are interested in designing and developing educational game applications by transforming the tiered learning system in Indonesia, with the expectation that we can increase the learning frequency and achievement.

\section{Literature Review}

Göbel et al. (2009) noted that the method to harmonized between storytelling, learning and gaming are:

- Storytelling: Using a mild description of the story in explaining the knowledge or information that is needed in a game

- Learning: Emphasizes knowledge and information to be conveyed, resulting in effective learning

- Gaming: Make the interesting interaction inside the game, so that the game can be achieved objectives

This harmonized method can be seen in Fig. 1. 


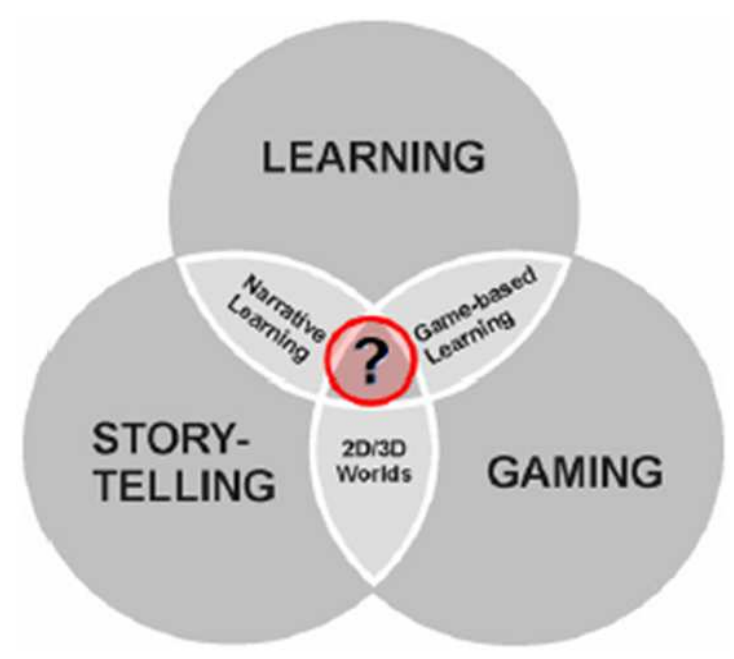

Fig. 1. Learning method Göbel et al. (2009)

\section{Game}

According to Schell (2008), quoted from Elliot and Brian, the game is a voluntary activity that occurs and to establish a controlled of system, where there is a contest of strength, limited by the rules to produce a result that is not going to win or defeat.

According to Schell (2008), the game is an interactive structure that has an internal value that requires players to survive up to the destination, there are 10 characteristics that must be possessed in a game, i.e.,:

- Game is played with a will of its own

- Games have goals

- Games have conflict/problem

- Games have rules

- Games can result in winning or losing conditions

- Games are interactive

- Game has challenges

- Games can create value internally within the game itself

- Games involving the player

- Game is a closed formal system

From the 10 characteristics above, Schell concludes the definition of the game is the activity to solving problems with using an approach that wants the fun attitude.

Meanwhile, according to Adams and Dormans (2012), the game is a type of play activity, conducted in the context of a pretended reality, in which the participants try to achieve at least one arbitrary, nontrivial goal by acting in accordance with rules.

\section{Element of Games}

According to Schell (2008), there are four basic elements in a game, i.e.,

\section{Mechanics}

Mechanics are procedures and rules in a game and also explain the purpose of a game. How users can try to achieve something or pass it, as well as what happens when a player tries to achieve.

\section{Story}

Story explains what happens inside the game. It can be linear and prescripted, or branched. Aesthetics can help narrator in telling the story.

\section{Aesthetics}

Aesthetics explains how to display pictures and sound. Aesthetics is very important in the game, because this is the element which directly interacts with the players.

\section{Technology}

Technology in the game does not always have to be advanced, the most important of these technologies is to fulfill requirement of the game created.

\section{Game Genres}

According to Fullerton (2008), the gameplay in the game is distinguished by its genre which now has an assortment. The genre also has a duty to limit the game designers to be creative in a more specific idea. Sometimes a game can contain more than one genre, called as hybrid genre. The following are the types of genres that exist in the game, namely:

\section{Action Games}

Action games involve the reactions of users when playing. A game with action type can provides a realtime experience with emphasis on limited time to perform physical tasks.

\section{Strategy Games}

Strategy games usually involve concentration and regulation of resources or units. Usual games with strategy type include conquest, exploration and exchange.

\section{Role-Playing Games}

Role-playing games include creating and developing characters in the game. Before playing the game, users create a character and then the character will be developed throughout the game according to the rule of the game. Massively Multiplayer Online Role-Playing Games (MMORPG) is a fraction of the genre of role-playing games. MMORPG is usually played online and support interactions among the players in the game. 


\section{Sport Games}

Sport games are sports-themed simulation game. Usually sports games adapt its rules from the real world. Some games are modified by the designer into new and exciting sports games.

\section{Racing/Driving Games}

Racing or driving games split into two types, namely type of arcade which can be played by all ages and racing simulation which can only be played by some quarters as a display or complex gameplay.

\section{Simulation/Building Games}

Simulation or building games are usually focused on the managing of existing resources, then combined to build something, whether it's to build a company or city. Unlike strategy games which are about conquering, simulation or building game are about growth.

\section{Flight and Other Simulations}

This type games usually provide based on simulation with the real world, such as flying planes, driving tanks and so on. Flight simulations are usually preferred by game users, because flight simulations make the user feel like flying a plane in the real world.

\section{Adventure Games}

Adventure games are about exploration, collecting items and solving puzzles. Typically the user is also asked to complete the mission in the game. Unlike roleplaying game where the characters in the game can grow, a character in the adventure games do not grow and cannot be modified.

\section{Edutaintment}

Edutainment game type is a fun way of learning. By entering the way of learning in the game, users can find a sense of fun and also gain knowledge while playing the game.

\section{Children's Games}

Children's games made specifically for children aged 2-12 tahun. Children's games usually contain elements of education, but which was devoted to children's entertainment.

\section{Casual Games}

Casual games are made to be enjoyed by everyone. Casual games do not contain an element of violence in it, therefore suitable casual games can be played by everyone.

\section{Game Design}

According to Adams (2013), game design is a process of:
- Imagining a game

- Defining the way it works

- Describing the elements that make up the game (conceptual, functional, artistic and others)

- Transmitting information about the game to the team who will build it

- Refining and tuning the game during development and testing

According to Rollings and Adams (2003), game design is broken down into three core sections (as seen in Fig. 2), namely:

\section{Core Mechanics}

Rules that define the rules of the game that form core mechanism of the game, or the basic rules of the game play. The mechanism of the core game is a translation from designer's vision into a set of rules which can be interpreted by a computer.

\section{Story and Narration}

All game has a story; the difference is the depth and complexity of the story. Narrative means a story that was delivered by the author or designer to the interactive game players. Narration is not interactive but a part of the story presentation.

\section{Interactivity}

Interactivity is a way for the players to see, hear and act in the real game. The topics that include interactivity among others: Graphics, sound, user interface, as well as everything which presented when playing experience. Interactivity has become a buzzword that connects with computer games.

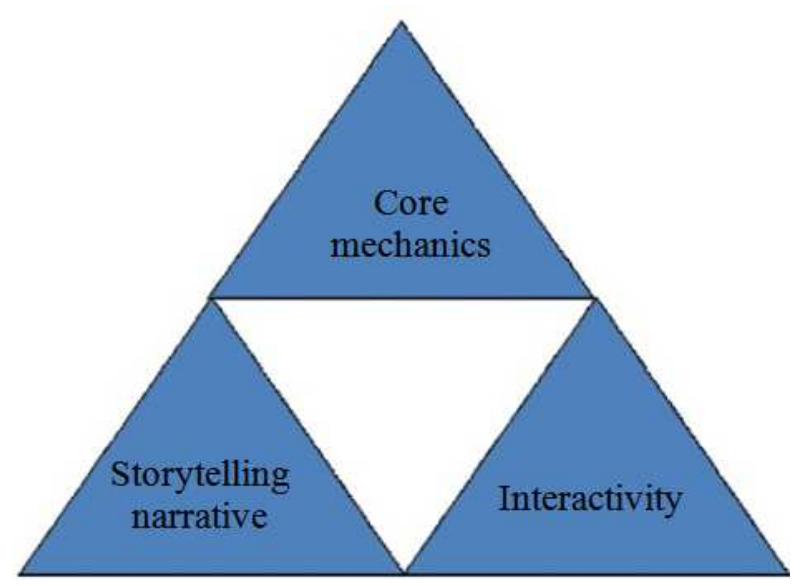

Fig. 2. Basic rules game design game design (Rollings and Adams, 2003) 


\section{Education Game}

According to $\mathrm{Mz}$ and Sy (2008), Game Based Learning (GBL) or educational game is a paradigm that uses games as a medium for to convey the content of the material. Educational game is all about harnessing the power of computer games to captivate and engage the user for a specific goal, such as to develop new knowledge and skills. Educational game is also defined as an application that uses the characteristics of video and computer games to create an interesting and in-depth experience of learning to provide specific learning objectives, outcomes and experience.

\section{Game Engine}

According to Goldstone (2009), the game engine is the skeleton of a game that we will create. Game engines which making decisions in determining the frame to the artwork in the scene. Modern 3D game engine now has a lot of scripts carefully so as to meet the needs of existing.

\section{Unity3D}

According to Goldstone (2009), Unity3D game makes production easier by providing some logic to build a gaming scenario envisioned. Unity3D is a game engine which easy to use, just create the object and the given function to execute that object. In each object has a variable, that the variable what must be understood in order to make a quality game.

The following are the parts contained in Unity3D:

\section{Assets}

Assets are a storage area in Unity3D. A place to store such as, sounds, images, videos, texture and all the objects that will be used in Unity3D and stored in assets.

\section{Scenes}

Scenes are an area that contains the contents in the game, such as making the display level, create menus, display loading.

\section{Game Objects}

When an object is removed from assets towards the scenes, the object will be object game, where the object can be moved, rotated and formed in accordance with the wishes.

\section{Components}

Components are part of the game objects, where the components to make a new reaction can be made to the game objects.

\section{Script}

The script is a way to write a programming language and make designed in-game actions. On the Unity3D there are three programming languages namely: C\#, JavaScript and BOO. The use of scripts in Unity3D using a special program called Mono that is already integrated.

\section{Prefabs}

Prefabs are where to store the type of game objects, so it can be easily propagated. The main goal of the prefabs is doesn't need to create objects that have been made before.

\section{Materials and Methods}

The methodology used in this study includes four main parts namely Literature Review Methods, Analysis Methods, Design and Implementation Methods. Literature review method done by reading books and articles from the library or the internet being used to add information for authors, help in making the application, as well as preparation of research report. With this method also, the author can make a proper theoretical basis. Analysis methods are shared through several stages such as surveying other similar games to collect data about favorite features in games and some other materials and give some questionnaire to respondent to collect information about respondent perspective about game. Design method that includes designing the game design, educational method and game features. Implementation method is the process to build the game design into a real game using Unity3D game engine.

\section{Results}

To gathering some information, we conducted some questionnaire to 116 high school students in Santa Patricia and Santo Kristoforus II High School in Jakarta, Indonesia. The questionnaire is about their daily and study activities. From questionnaire that conducted, there are several information gathered:

- There are 9 subjects in Indonesia learning system as the core subject

- Indonesian language is the most favorite subject and Mathematic is the least preferred by the respondents

- Respondents only use 1-2 $\mathrm{h}$ in their time at home to studying

- Respondents use more than $2 \mathrm{~h}$ in their time at home to playing games as entertainment

- Respondents love the battle theme games with RPG genre.

- Most of respondents wants to play education based game if it's being made

\section{Experiment}

Based on the information gathered, we create an education based game namely "Book of Phantasm". This 
game is on RPG genre that uses4 heroes with some differences in characteristic and stats (strength, agility, intelligence, health points, energy and stamina) to wandering around the game world.

The game world dividedto 5 continents (SMA 1 (High School 1), SMA 2 (High School 2), SMA 3 (High School 3), Regullus Village (Shops) and Valhala (Fighting Arena)) as seen in Fig. 3.

The SMA 1, SMA 2 and SMA 3 continents are used for player to take some quizzes and go to libraries. The question uses in the quiz are gathered from high school exam books divided in 9 subjects in Indonesian learning system. While in the library, player can search the information about the subjects.

The subjects used are Mat (mathematics), Bahasa (Indonesian), Inggris (English), Biologi (Biology), Fisika (Physics), Kimia (Chemistry), Geografi (Geography), Ekonomi (Economics), Sosiologi (Social Study).

In Regulus Village, player can go to the shop to buy and sell items and learning magic. There are two types of money used in thisgame, gold coin and subject coins (Fig. 4). The gold coin used in shop to buy some items, but subject coin is used to learning magic. Player can get the gold coin from battle with monster in arena, but the subject coins can only be obtained from the prize in quiz.

Valhala village are used for player as an arena to do battle with some monster to strengthen up the player's character.

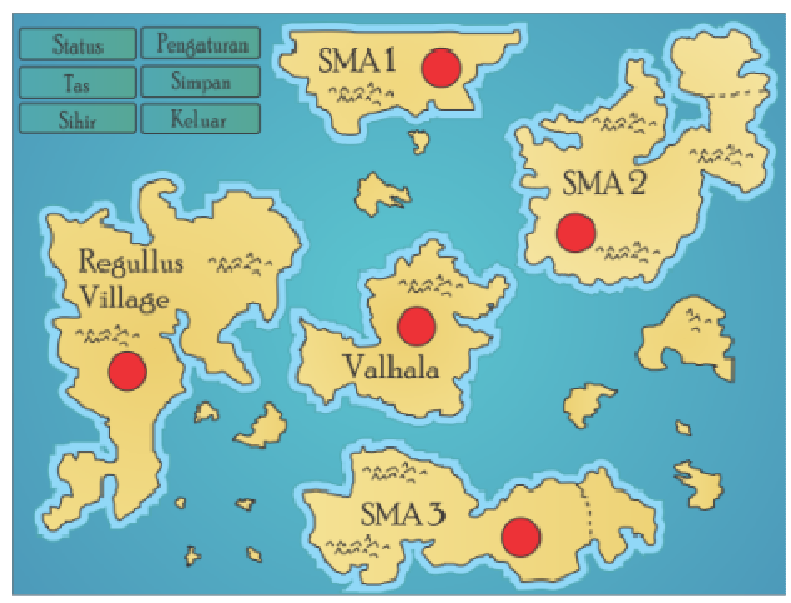

Fig. 3. "Book of phantasm" world continents

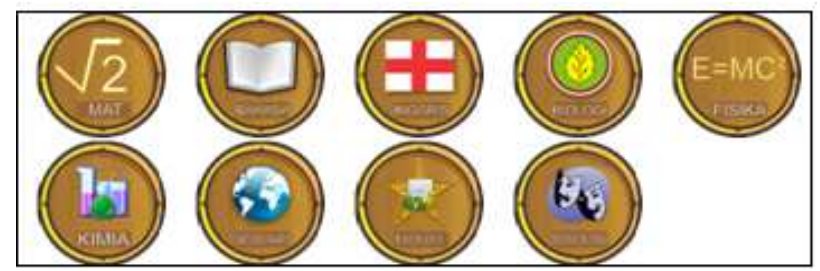

Fig. 4. Subject coin

\section{Evaluation}

User evaluation has been done with giving some questionnaire about to Santa Patricia and Santo Kristoforus II High School students in Jakarta, Indonesia. The questionnaire is about the prototype of game "Book of Phantasm" that given to them a week before.

From that evaluation $94 \%$ of respondents said that this game is interesting to play, $79 \%$ of respondents said that this game easy to play and $94 \%$ of respondents said that this game can be used as a learning media to increasing their learning frequency and increasing their knowledge. With this game, they use $4-5 \mathrm{~h}$ to study some materials through games.

\section{Conclusion}

According to evaluation to some respondent in Santa Patricia and Santo Kristoforus II High School in Jakarta, Indonesia, Game "Book of Phantasm" can be a learning tool to increasing learning frequency, mastering materials, student interest in learning and knowledge to the user.

From the evaluation, the learning frequency of $94 \%$ of respondents increased, student interest in learning of 97\% respondents increased and 97\% respondents had increased their knowledge with "Book of Phantasm".

\section{Funding Information}

The authors have no support or funding to report.

\section{Author's Contributions}

All authors equally contributed in this work.

\section{Ethics}

This article is original and contains unpublished material. The corresponding author confirms that all of the other authors have read and approved the manuscript and no ethical issues involved.

\section{References}

Adams, E. and J. Dormans, 2012. Game Mechanics: Advanced Game Design. 1st Edn., Berkeley, New Riders, ISBN-10: 0321820274, pp: 353.

Adams, E., 2013. Fundamentals of Game Design. 3rd Edn., New Riders, USA, ISBN-10: 0321929675, pp: 576.

Fullerton, T., 2008. Game Design Workshop: A Playcentric Approach to Creating Innovative Game. 2nd Edn., Morgan Kaufmann, USA, ISBN-10: 0240809742, pp: 496. 
Göbel, S., F. Mehm S. Radke and R. Steinmetz, 2009. 80Days: Adaptive digital storytelling for digital educational games. Proceedings of the 2nd International Workshop on Story-Telling and Educational Games, (TEG’ 09), CEUR-WS, pp: 1-10.

Goldstone, W., 2009. Unity Game Development Essentials. 1st Edn., Packt Publishing Ltd, Birmingham, ISBN-10: 1847198198, pp: 298.

Irianto, E.S., 2009. Penerapan pembelajaran multimedia untuk meningkatkan hasil belajar IPA bagi siswa kelas VIII SMPN 1 Rembang tahun pelajaran 2007/2008. Widyatama Jurnal Pendidikan, 6: 31-42.

Mz, N.A. and W. Sy, 2008. Game based learning model for history courseware: A preliminary analysis. Proceedings of the International Symposium on Information Technology, Aug. 26-28, IEEE Xplore Press, Kuala Lumpur, pp: 1-8.

DOI: 10.1109/ITSIM.2008.4631565
Rollings, A. and E. Adams, 2003. Andrew Rollings and Ernest Adams on Game Design. 1st Edn., New Riders, USA, ISBN-10: 1592730019, pp: 621.

Schell, J., 2008. The Art of Game Design: A Book of Lenses. 1st Edn., CRC Press, USA, ISBN-10: 0123694965, pp: 520.

Vaughan, T., 2010. Multimedia: Making it Work. 8th Edn., McGraw Hill, USA, ISBN-10: 0071748466, pp: 478. 